\section{Time to use neuroscience findings in teacher training}

\section{SIR - Your Editorial "Bringing neuroscience} to the classroom" (Nature 435, 1138; 2005) and News Feature "Big plans for little brains" (Nature 435, 1156-1158; 2005), on the emerging connections between education and cognitive neuroscience, are both hopeful and critical at once. There is currently a strong emphasis on the need for research findings to be both immediately available, and directly applicable to the classroom. This inadvertently sets high expectations which, if not met, could lead to the quick erosion of this developing field.

I believe it is time to think about the interactions between education and cognitive neuroscience in broader terms. In addition to conducting research projects such as those described in your Editorial and News Feature, it is now essential to begin integrating the teaching of scientific evidence from cognitive neuroscience into teachertraining and further-education programmes. This would facilitate the creation of a 'researcher-practitioner' model in the field of education. The US National Science Foundation centre at Boston University and the LearnLab project, as described in your News Feature, have made a start in this direction, but more of these types of projects are needed to create the basis for fruitful exchanges and collaborations between cognitive neuroscientists and educational practitioners.

The 'science of learning' needs to strengthen its conceptual backbone and put forth a broad set of aims, while permitting development to occur. If this is done, rejection on the basis of 'lack of direct application' can be avoided and rich outcomes anticipated.

Daniel Ansari

Department of Education, Dartmouth College, Hanover,

New Hampshire 003755, USA

\section{Embryo's moral status is unaffected by alteration}

SIR - Both proponents and opponents of embryonic stem-cell research should object to William Hurlbut's proposal for nuclear transfer embryos to be genetically engineered to block their capacity for development into human babies ("Altered embryos offered as solution to stem-cell rift ${ }^{\text {n }}$ Nature 436, 309; 2005).

In describing such material as 'embryo-like entities', Hurlbut misses the point that that is what nuclear transfer embryos already are. Indeed, calling them 'embryos' seems somewhat tenuous, considering that they are not the products of a sexual process; nor are they clones. But, whatever they are called, it is inescapable that any potential for development to babies can only be realized by implantation into the wall of a uterus. Engineering then seems pointless: in order to block the capacity to develop into a baby, simply don't implant.

Deliberately altering genotype could have important consequences. Disablement of multitasking growth factors, for example, may interfere with cell-signalling mechanisms, thus affecting lab protocols for directed differentiation towards specialized cells in sufficient numbers for therapy.

From an ethical standpoint, intentionally downgrading the moral status of human embryos, in order to render them suitable for research that was otherwise deemed immoral, would be dissimulation.

We should be aiming to make this science more understandable and accessible to allow for proper informed debate. Instead, Hurlbut's complicating proposal is selfcontradictory and detrimental to the progression of important human embryonic stem-cell research.

Lee Turnpenny

Human Genetics Division,

University of Southampton,

Southampton SO16 6YD, UK

\section{Industrial practices set no standard for science}

Ian Taylor, in Correspondence (Nature 436, $626 ; 2005$ ), argues that a number of practices considered scientific misconduct in academia are acceptable to industry. In so doing, he may highlight the existing gulf between academia and industry, but in no way does he provide any support for the erosion of scientific principles, which should be defended to the utmost.

Applying the ideas of others may be commercially prudent, but it is not 'science'. Building on current thought to produce new knowledge is science; simply applying it in a commercial setting is business. Similarly, it may be proper practice to withhold methodologies in an effort to protect proprietary information, but doing so reduces publications to the level of nonscientific anecdotal reports. If an experiment is published without full details of the methodologies, then not only is it impossible to reproduce the experiment, but the results, and indeed the methods, cannot be built upon by the wider scientific community.

Commercial and scientific interests may contribute one to the other, but their ends are different. I see no reason for academic research to adopt more commercial practices. Indeed, Taylor's examples lend support to the opposite view - as well as to a proper scepticism towards science conducted by commercial enterprises.

Steven Tait

Edinburgh Research and Innovation,

University of Edinburgh,

1-7 Roxburgh Street,

Edinburgh EH8 9TA, Scotland, UK

\section{Farming need not replace fishing if stocks are rebuilt}

SIR - In his Commentary article, ${ }^{\alpha}$ When will we tame the oceans?" (Nature 436, 175-176; 2005), John Marra foresees mariculture as an important contributor to global food production and as a solution to overfishing. He argues that the world's fisheries should be replaced by large-scale domestication of the oceans.

We agree that aquaculture is playing an increasingly important role in world fish supply. But a careful distinction must be made between the aquaculture of freshwater fishes, molluscs and plants - which is primarily low-tech and low-impact, and helps feed people in developing countries and the high-tech mariculture of carnivorous finfish advocated by Marra, which serves luxury food markets. It is unlikely that lowincome families will ever taste maricultured tuna, salmon or cod. Indeed, these people's protein supply may diminish as the market for many small food fishes becomes cornered to provide mariculture fish feed.

Farming carnivores also results in a net loss of food because of inefficient energy conversion between trophic levels, as Marra acknowledges. Tuna farming, therefore, is not like herding cattle it is the ecological equivalent of trapping wild shrews and foxes to feed caged wolves.

Fisheries and the wild populations that supply them should not be abandoned. Instead, serious effort should be focused on rebuilding depleted fish populations by creating large marine reserves and reducing total fishing capacity. Proper management of wild marine life could yield remarkable results, but-ironically_requires what Marra lists as a precondition for his vision of domesticated oceans: the political will to implement changes and create transnational agreements on shared ocean use. When we finally garner this political will, should we not use it to restore productive, biologically diverse ecosystems, rather than to risk further degrading the oceans?

Offshore mariculture is not ${ }^{\alpha}$ inevitable. It is a course of action that can be chosen or not.

Julia K. Baum, Jana M. McPherson,

Ransom A. Myers

Department of Biology,

Dalhousie University,

Halifax, Nova Scotia B3H 4J1, Canada 